1991 Particle Accelerator Conf., San Francisco, CA, 5/6-9/91.

\title{
ANALYSIS OF MAGNETIC FIELD MEASUREMENT RESULTS FOR THE AGS BOOSTER MAGNETS*
}

\author{
E.Bleser, R.Them \\ $B N L--45425$ \\ AGS Department, Brookhaven National Laboratory \\ Upton, NY 11973 \\ DE91 013599
}

\section{SUMMARY}

Magnetic field measuremeats have been made on nearly 200 conventional magnets that have been installed in the AGS Booster and its associated transfer lines. The measurements were intended to monitor the quality of the magnets being produced and to check the performance of each magnet before installation. The magnetic measurements effort led to certain improvements in the manufacturing process, which then subsequently produced very good, very uniform magnets. The integrated dipole fields of the 36 booster dipoles are uniform to 1.5 parts in ten thousand. The magnetic measurements indicate that the quadrupoles were manufactured to an accuracy of 3 ten thousandths of an inch, which is better than we can physically measure.

\section{INTRODUCTION}

At Brookhaven National Laboratory a Booster Accelerator is being added to the AGS complex. [1] All the magnets are in place and circulating beam is expected in a few weeks. The Booster is rapid cycling, is 200 meters in circumference, and is intended to 1.) quintuple the AGS proton intensity by injecting $2.25 \mathrm{GeV} / \mathrm{c}$ protons, and 2.) inject ions as heavy as gold into the AGS. Since high intensity is an important goal of the Booster, great care was taken in the design and fabrication of the Booster magnets. This note summarizes the results from the production testing of these magnets.[2]

The Booster and its associated transfer lines require about 300 individual magnets of about $\mathbf{3 0}$ distinct designs. Table $\mathbb{1}$ lists some of the parameters of the major magnet systems. Our goal was to measure every magnet. The lesson we learned is that systems can be developed to routinely and efficiently measure the important groups of magnets, but those that occur in small numbers or have very special measurement requirements frequently slip through the cracks.

*Work performed under the auspices of the U.S. Dept. of Energy.

\section{THE BOOSTER DIPOLE}

The Booster dipole is a curved 10 degree sector magnet. Table 2 gives the specified and the measured field shape. Figure I shows a typical field shape measurement.

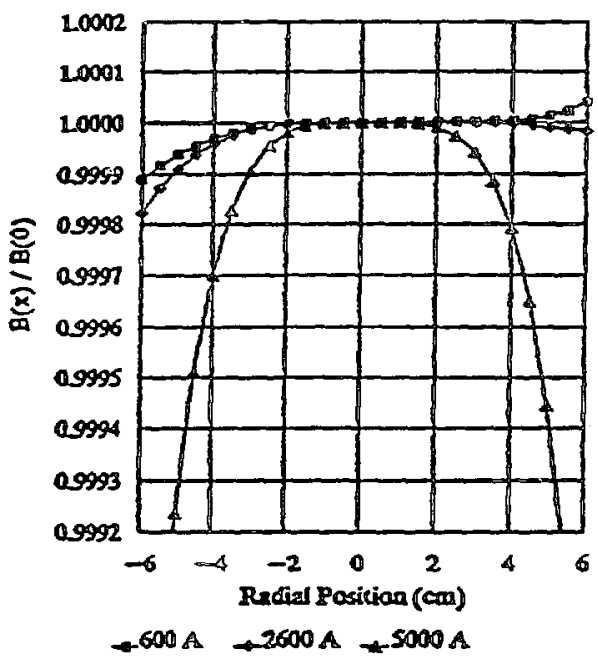

Figure 1. Magnetic profile, at 3 different currents, of a Booster dipole magnet taken over the entire leagth of the magnet. In this plot a quadrupole term and a sexurpole term. equivalent to the average values of those terms in all the dipoles, have been removed, since they can be corrected for in Booster operation. The remaining field is good to one part in 10,000 over 10 centimeters at low field and over 5 centime ters at high field.

Of some interest is our degree of success in controlling the variation from magnet to magnet of the integrated dipole field strength. This was specified to have an rms variation of 1.5 parts in ten thousand. We claim to have achieved this. Three different Eets of measurements were made on each dipole: 1.) A DC NMR measurement st the magnet center. These results were good to one part in ten thousand. 2.) A short (1 meter) rotating coil used in nine different positions to map the field. The results here are good to 3 parts in ten thousand and attest to the care of the technicians in placing the 
TABLE 1 BOOSTER MAIN MAGNET SYSTEMS

\begin{tabular}{|c|c|c|c|c|c|}
\hline TYPE & DIPOLE & QUAD & QUAD & SEXT & \\
\hline $\begin{array}{l}\text { NAME } \\
\text { NUMBER INSTALLED } \\
\text { LENGTH } \\
\text { GAP OR DLAMETER } \\
\text { TURNS PER POLE } \\
\text { IOmX } \\
\text { POLE TIP FIELD } \\
\text { AT IERAX }\end{array}$ & $\begin{array}{l}\text { BMD } \\
36 \\
2.380 \\
8.255 \\
8 \\
5700 \\
13.5\end{array}$ & $\begin{array}{l}\text { BMQL } \\
24 \\
0.438 \\
16.510 \\
5 \\
5700 \\
8.4\end{array}$ & $\begin{array}{l}\text { BMQS } \\
24 \\
0.426 \\
16.510 \\
5 \\
5700 \\
8.4\end{array}$ & $\begin{array}{l}\text { BNS } \\
48 \\
0.076 \\
16.510 \\
8 \\
300 \\
2.1\end{array}$ & $\begin{array}{l}\text { meters } \\
\text { centimeters } \\
\text { Amperes } \\
\text { kiloGxuss }\end{array}$ \\
\hline
\end{tabular}

coil. 3.) A long coil measurement of the ramped field. These measurements gave us the integrated strength of the magnet, which is the number of interest for Booster operations and is the number we quote for overall magnet repeatability. The distribution of the results has a sigma of 2.7 parts per ten thousand. The system was designed to make absolute measurements on each magnet rather than doing comparative measurements of each magnet against \& standard magnet. The ramping power supply needed periodic adjustments, which we believe were sufficient to affect the results at the level of a few parts in ten thousand as determined by periodic measurements of a standard magnet. Therefore, the number we quote, 1.5 parts in ten thousand results from some analysis and adjustment of the raw data. The point is that an accuracy of one or two parts in ten thousand is very hard and even when the manufacturing group achieves this accuracy by carefully coatrolling the liength and weight of each magnet, demonstrating it by field measurement can still be a problem.

TABLE 2

RANDOM FIED ERRORS IN THE BOOSTER DFOLES

\begin{tabular}{|c|c|c|c|}
\hline TERM & $\begin{array}{l}\text { SPECIFIED } \\
\text { TOLERANCE }\end{array}$ & $\begin{array}{l}\text { MEASURED nim } \\
\text { A } 2600 \text { Amps }\end{array}$ & UNITS \\
\hline SBOAd? & \multirow{2}{*}{15} & \multirow{2}{*}{1.5} & \multirow{2}{*}{$10^{-4}$} \\
\hline SBOadl & & & \\
\hline B1/BO & 2 & 0.91 & $10^{5} \mathrm{~cm}^{-1}$ \\
\hline E2/BO & 5 & 0.89 & $10^{6} \mathrm{cos}^{2}$ \\
\hline $\mathrm{B} 3 / \mathrm{BO}$ & 7 & 0.14 & $10^{6} \mathrm{~cm}^{9}$ \\
\hline BUBO & 1 & 0.01 & $10^{6} \mathrm{~cm}^{-4}$ \\
\hline $\mathrm{BS} / \mathrm{BO}$ & 1 & 0.06 & $10^{-7} \mathrm{~cm}^{-5}$ \\
\hline
\end{tabular}

The Booster will operate at up to 7.5 magnet cycles per second, which means that eddy currents induced in the vacuum chamber will contribule significantly to the magnetic fields, in particular to the sextupole term in the dipoles. A set of windings was designed to be installed on the vacuum chamber to carry a current to cancel the eddy current effects.[3] This current is driven by four turns wound around the dipole poles. This system has the advantages of canceling the sextupole at its origins, of decoupling the correction system from a dependence on vacuum chamber placement, and since it is entirely passive, of decoupling the correction system from a dependence on ramp rate settings. Figure 2 shows the measured induced sextupole as a function of the ramp rate with and without the correction coils connected. At a constant ramp rate the compensation is a remarkably good $99.5 \%$. The compensating coil does produce higher harmonics, decapole, 14-pole etc., but the effects are small at the center of the magnet.

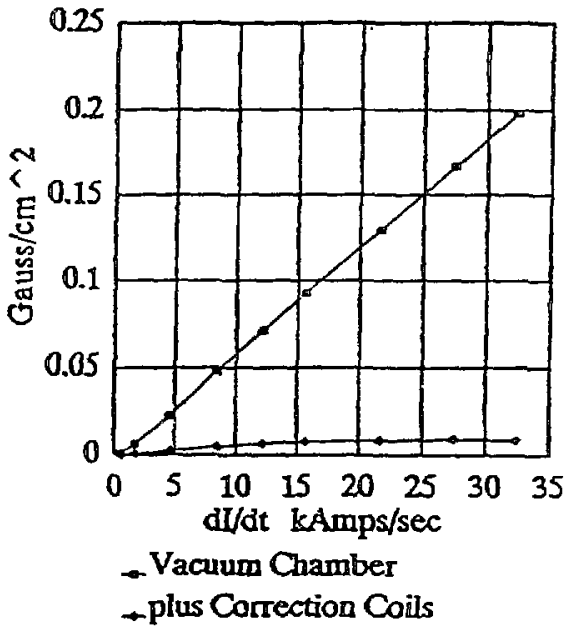

Figure 2. The measured induced sextupole field in a dipole as a function of ramp rate with and without the passive correction coils connected. Most of this sextupole is due to eddy currents in the vacurum chamber. The corrected sextupole field is less than the random allowed sextupole field.

\section{THE BOOSTER OUADRÜPOLE}

The Booster uses two types of quadnpoles magnets, the horizontally focusing magnets being slightly shorter than the vertically forussing to compensate the horizontal focussing of the sector dipoles. Quadrant laminations are assembled into blocks and then the foir quadrant blocks are assembled into a magnet. The initial assembly procedures produced blocks that were insufficiently rigid resulting in poor assemblies and very poor test results. The mechanicall engineering staff very effectively solved the problem and produced a system that is now assembled rather like a watch. The result is a magnet that is very uniform from sample to sample. The controlling 
requirement was the uniformity of the integrated gradient, in meeting tolerances on that, the field shape automatically became very uniform from magnet to magnet. The same care in controlling block length and weight that was applied to the dipoles was applied to the quadrupoles. Table 3 summarizes the quadrupole results.

TABLE 3

RANDOM FIELD ERRORS IN THE BOOSTER QUADRUPOLES

\begin{tabular}{|c|c|c|c|}
\hline TERM & $\begin{array}{l}\text { SPECIFIED } \\
\text { TOLERANCE }\end{array}$ & $\begin{array}{l}\text { MEASURED rms } \\
\text { at } 2600 \text { Amps }\end{array}$ & UNITS \\
\hline 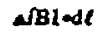 & \multirow{2}{*}{6} & \multirow{2}{*}{1.6} & \multirow{2}{*}{$10^{-5}$} \\
\hline Fladf & & & \\
\hline BO/BI & 8 & 0.7 & $1 \sigma^{7} \mathrm{~cm}^{-2}$ \\
\hline $\mathbf{B 3} / \mathbf{B I}$ & 6 & 0.01 & $10^{-6} \mathrm{~cm}^{-2}$ \\
\hline$B A / B 1$ & 2 & 0.01 & $10^{-7} \mathrm{~cm}^{-3}$ \\
\hline BS/BI & 8 & 0.02 & $10^{-8} \mathrm{~cm}^{-4}$ \\
\hline
\end{tabular}

\section{THE BOOSTER SEXTUPOLE}

The Booster Sextupole was manufactured entirely by an outside vendor who delivered 52 completed magneis to us. Table 4 summarizes the magnet requirements and the measurement results. The magnet easily meets the stated specifications, and we suspect could have done even better with tighter control of the length and weight of the magnet cores.

TABLE 4

RANDOM FIECD ERRORS IN THE BOOSTER SEXTUPOLES

\begin{tabular}{|c|c|c|c|}
\hline TERM & $\begin{array}{l}\text { SPECIFIED } \\
\text { TOLERANCE }\end{array}$ & $\begin{array}{l}\text { MEASURED rms } \\
\text { at } 300 \text { Amp: }\end{array}$ & UNITS \\
\hline d be2edl & \multirow{2}{*}{9} & \multirow{2}{*}{3} & \multirow{2}{*}{$10^{3}$} \\
\hline ABzedf & & & \\
\hline B3/B2 & 3 & 0.02 & $10^{2} \cos ^{-1}$ \\
\hline B4/B2 & 2 & 0.07 & $10^{3} \mathrm{~cm}^{-2}$ \\
\hline BS/B2 & 3 & 0.2 & $10^{-4} \mathrm{~cm}^{-3}$ \\
\hline
\end{tabular}

\section{CONCLUSIONS}

Our conclusions are that the booster magnets all meet specifications easily. Copper and steel magnets can be manufactured fairly readily to produce results uniform to the order of one part in ten thousand. However, to achieve these results each step of the process must be controlled rather carefully, in particular the length, weight, and gap of the magnet. Measuring to such good accuracy over a long period of time then requires very good equipment and carefully established calibration standards.

\section{ACKNOWLEDGEMENTS}

Many people contributed to the specification, design, construction, and testing of the booster magnets. The authors of the present note were solely involved in analyzing and monitoring the measurement results. As such they frequently raised nitpicking criticisms of the efforts of others and therefore would like to take this oppcrtunity to congratulate them on a job well done.

\section{REFERENCES}

[1] W.T.Weng, "Construction and Early Commissioning Results of the AGS Booster," Paper CGC1 these procexdings.

[2] J.Herrera, G.Ganetis, R.Hogue, E.Rogers, P.Wanderer, and E.Willen, "Measurement of the Magnetic Field Coefficients of Particle Accelerator Magnets," Proceedings of the 1989 IEEE Particle Accelerator Conference, Chicago, Illinois, March 1989, pp 1774-1776.

[3] G.T.Danby and J.W. Jackson, "Vacuum Chamber Eddy Current Self-Correction for the AGS Booster Accelerator," Particle Accelerators, Vol. 27, pp 33-38, 1990.

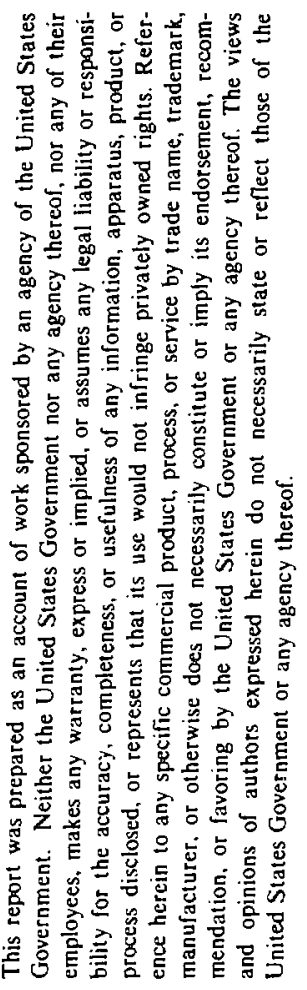

